\title{
Evaluation of egg quality traits of endangered Nicobari fowl and its crosses under intensive and backyard system of Andaman and Nicobar I slands, India
}

\author{
N. C. Choudhuri'1,2, G. Paul ${ }^{1}$, A. Kundu², M. S. Kundu², Arun Kumar De² and Nagesh Ram²
}

1. Department of Physiology, University of Kalyani, Kalyani, West Bengal, India; 2. Department of Animal Sciences, Central Island Agricultural Research Institute, Port Blair, Andaman and Nicobar Islands, India.

Corresponding author: N. C. Choudhuri, e-mail: ncc_pb@rediffmail.com,

GP: gpaul.kalyani@rediffmail.com,AK: drakundu1@yahoo.com, MSK: mkundu47@rediffmail.com, AKD: biotech.cari@gmail.com, NR: nageshramkvk@yahoo.co.in

Received: 19-05-2014, Revised: 22-07-2014, Accepted: 02-08-2014, Published online: 19-09-2014

doi: 10.14202/vetworld.2014.693-697. How to cite this article: Choudhuri NC, Paul G, Kundu A, Kundu MS, Kumar De A, Ram N. (2014) Evaluation of egg quality traits of endangered Nicobari fowl and its crosses under intensive and backyard system of Andaman and Nicobar Islands, India, Veterinary World 7(9): 693-697.

\begin{abstract}
Aim: In the present study, egg quality traits of endangered Nicobari fowl and its crosses (Nicorock and Nishibari) were evaluated under intensive (deep litter) as well as backyard system, in the regions of Andaman and Nicobar Islands, India.

Materials and Methods: Fresh eggs (15) of all the three genetic groups of birds were collected randomly from institute farm (intensive system) and from farmers' field. The eggs were collected from adult birds (50 weeks of age) 3 times with 5 in number in each time. All the genetic groups of birds were subjected to same husbandry practices. The eggs were subjected to external and internal quality parameters study.

Results: The effect of genetic groups on egg weight was significant $(\mathrm{p}<0.05)$ for all the groups. Nicorock had significantly higher egg weight $(\mathrm{g})(56.79 \pm 0.77)$ in comparison to Nicobari $(53.20 \pm 0.34)$ and Nishibari $(48.98 \pm 0.22)$ under intensive system of management. Under backyard condition, the egg weight (g) of Nicorock (48.60 \pm 1.04$)$ was significantly higher than Nicobari but not with Nishibari. In general, the egg weight was found less under backyard system than intensive system that might be due to scavenging nature of birds. Egg length, egg width and shape index differed significantly $(\mathrm{p}<0.05)$ among the genetic groups. Yolk index of Nicorock was significantly $(p<0.05)$ higher than Nishibari under intensive as well as backyard condition. The shell thickness varied significantly $(\mathrm{p}<0.05)$ among different genetic groups. Haugh unit of Nicorock was significantly $(\mathrm{p}<0.05)$ lower in comparison to Nicobari and Nishibari under intensive system, but did not vary significantly among genetic groups under backyard condition.
\end{abstract}

Conclusions: The study revealed that there was a significant effect of genetic groups on different egg quality traits; both in intensive system and backyard condition.

Keywords: egg quality parameters, nicobari fowl, nishibari, nicorock, Andaman and Nicobar Islands.

\section{I ntroduction}

Backyard poultry farming is gaining wider importance and acceptance among the rural people of tropical countries as a source of income generation and supplementary livelihood activity [1]. Total poultry population of Andaman and Nicobar Islands, India is 10.8 lakhs according to 2012 census (AH \& VS, Andaman and Nicobar Administration, personal communication) and consists mostly of indigenous varieties [2]. Though very large population of birds is available, there is an acute shortage of egg and chicken in these Islands as the demand of animal protein is increasing day by day due to heavy inflow of tourists and a high percentage of non-vegetarian population [2]. The quality of the egg is one of the important considerations for the consumers and eggs of indigenous birds generally fetch higher price than eggs from commercial layer birds in the local market of Andaman and Nicobar islands.

Copyright: The authors. This article is an open access article licensed under the terms of the Creative Commons Attributin License (http:// creative commons.org/licenses/by/2.0) which permits unrestricted use, distribution and reproduction in any medium, provided the work is properly cited.
Therefore, it is utmost important to evaluate the egg quality parameters of the indigenous birds of Andaman and Nicobar islands.

Andaman and Nicobar islands are the habitat of many indigenous poultry varieties. Among them, Nicobari fowl draws most attention due to its several valuable characteristics i.e., it is highest egg producer among all Indian indigenous chicken breeds, resistant to some of the deadliest diseases of poultry, is very much adaptable to the local conditions of these Islands and can fly well to avoid predators [3]. They lay 128-142 eggs/annum under free range condition and attain a body weight of $1392 \mathrm{~g}$ in 184 days [3]. Nicorock and Nishibari were developed by the institute through cross breeding of Black Rock with Black Nicobari and Brown Nicobari with White leghorn respectively. Nishibari produces 160-170 eggs/year under backyard, and Nicorock produces 130-140 eggs/year with an average of $1 \mathrm{~kg}$ body weight at 12 weeks of age under backyard system [2]. They are easily adaptable to the local environment.

The information on the structure of the egg and its various quality parameters are essential for better 
understanding of fertility, embryo development and diseases of the poultry. Many factors influence the egg quality, i.e., breed/strain/variety, temperature, relative humidity, rearing practices and season [4]. Differences in egg quality traits have been reported by various workers [5-7]. Though lot of work has been carried out on egg quality traits, the information on egg quality traits of Nicobari and its crosses under deep litter and backyard farming are limited.

The present study was aimed to assess the egg quality traits of Nicobari and its crosses (Nicorock and Nishibari) under deep litter and backyard farming system, in the regions of Andaman and Nicobar Islands, India.

\section{Materials and Methods}

\section{Ethical approval}

The present experiment complies with all relevant institutional and national animal welfare guidelines and policies and the experiment has been conducted as per the approval of the Institute Animal Ethics Committee, Central Island Agricultural Research Institute, Port Blair.

\section{Birds}

In the present experiment, three genetic strains of birds were utilized viz. Nicobari, Nishibari and Nicorock. Egg quality traits were evaluated under intensive and backyard system of management. Under intensive system (deep litter system), all the birds were wing banded and reared in equal numbers over different pens providing uniform management conditions. Feed and water were provided as per Bureau of Indian Standard specifications. Ambient temperature, lighting, ventilation and other environmental conditions were provided according to the recommended standards. Chick starter ration was provided to the chicks up to 8 weeks of age. Subsequently, the grower ration during growing and layer ration during laying period were provided. The composition of starter,

Table-1: Ingredients and nutrient composition of the poultry feeds used in the study.

\begin{tabular}{lccc}
\hline Ingredient & $\begin{array}{c}\text { Starter } \\
(\mathbf{K g )}\end{array}$ & $\begin{array}{c}\text { Grower } \\
(\mathbf{K g})\end{array}$ & $\begin{array}{c}\text { Layer } \\
(\mathbf{K g})\end{array}$ \\
\hline Maize & 59.15 & 58.95 & 60.55 \\
DORB & 0 & 5.99 & 4.97 \\
Soyabean & 31.89 & 20.80 & 18.01 \\
Fish meal (43\% protein) & 0 & 0 & 8.0 \\
Sunflower meal & 5.20 & 11.08 & 6.17 \\
CALCITE (Calcium & 1.6 & 2 & 2 \\
D-pantothenate) & & & \\
DCP & 1.6 & 1.4 & 0.4 \\
DLM & 0.2 & 0.11 & 0.1 \\
LY & 0.06 & 0 & 0 \\
Salt & 0.4 & 0.4 & 0.1 \\
ME (kcal/kg) & 2781 & 2642 & 2560 \\
Crude protein (\%) & 20.53 & 17.9 & 18 \\
Calcium \% & 0.99 & 1.1 & 3.82 \\
A. phosphorus\% & 0.46 & 0.42 & 0.42 \\
\hline
\end{tabular}

$\mathrm{DORB}=$ Deoiled rice bran, $\mathrm{DCP}=\mathrm{Di}$-calcium phosphate, $\mathrm{DLM}=\mathrm{DL}$-methionine, $\mathrm{LY}=$ Lysine grower and layer ration is given in Table-1. For backyard system, eggs were collected from farmers' field where birds were maintained under uniform management conditions.

\section{Measurement of egg quality traits}

Egg quality traits evaluated were egg weight (g), egg length (mm), egg width (mm), shape index, yolk diameter $(\mathrm{mm})$, yolk height $(\mathrm{mm})$, yolk weight $(\mathrm{g})$, yolk percentage, yolk index, albumen height $(\mathrm{mm})$, albumen weight (g), albumen percentage, shell weight (g), shell thickness (mm), shell percentage and Haugh unit. The traits were determined following standard procedure and formulae. The measurements were taken using digital venire calipers (least count $0.01 \mathrm{~mm}$ ). Various indices of egg quality traits estimated are as follows:

A. Shape Index $=$ Maximum width/Maximum length $\times 100$

B. Albumen Index $=$ Albumen height/Average Albumin width $\times 100$

C. Haugh unit $=100 \log \left[\mathrm{H}-\frac{\sqrt{\mathrm{G}\left(30 \mathrm{~W}^{0.37}-100\right)}}{100}+1.9\right]$

$\mathrm{H}=$ Albumen height in millimeters

$\mathrm{G}=32.2$ (gravitational constant)

$\mathrm{W}=$ Weight of egg in gram

D. Yolk index $=$ Height of yolk/diameter $(\mathrm{mm})$.

\section{Statistical analysis}

All the collected data were analyzed with the SAS Software Release 8.2 (SAS Inst., Inc., Cray, NC) with the Proc GLM and Proc CORR procedures. The differences between treatments were analyzed using a one-way analysis of variance. Differences with a confidence level of 0.05 or less were considered to be significant.

\section{Results}

Egg quality traits of different genetic strains reared under intensive system of management are presented in Table-2. Under intensive system, egg weight of Nicorock (56.79 $\pm 0.77 \mathrm{~g})$ was found significantly $(\mathrm{p}<0.05)$ higher in comparison to Nicobari $(53.20 \pm 0.34)$ and Nishibari (48.98 \pm 0.22$)$. Yolk diameter, yolk height and yolk weight of Nicorock were also significantly higher in comparison to Nicobari and Nishibari; whereas, albumen height of Nicorock was significantly lower in comparison to other genetic strains. A significantly higher shell thickness was observed in Nicobari in comparison to the other strains though Nicorock and Nishibari did not differ in shell thickness significantly. No significant variations among three strains were found in respect to shape index. Yolk index of Nicorock was significantly higher than Nicobari, but did not vary significantly with Nishibari. Nicorock and Nishibari also did not differ significantly in respect to yolk index. Haugh unit of Nicorock was significantly lower in comparison to 
Table-2: Egg quality traits of Nicobari and Cross Nicobari fowl under intensive system of management.

\begin{tabular}{|c|c|c|c|}
\hline Par & $\begin{array}{c}\text { Nicobari } \\
\text { (15) }\end{array}$ & $\begin{array}{c}\text { Nicorock } \\
\text { (15) }\end{array}$ & $\begin{array}{l}\text { Nishibari } \\
\text { (15) }\end{array}$ \\
\hline & $4^{b}$ & 56.7 & $4 \varepsilon$ \\
\hline & & & \\
\hline & & & \\
\hline & & & \\
\hline er & & & \\
\hline eight & & 13 & \\
\hline & & & \\
\hline & & & \\
\hline & & & \\
\hline ght & & & \\
\hline en weight & $31.41 \pm 0.23^{a}$ & $31.98 \pm$ & 27 \\
\hline & & & \\
\hline & & & \\
\hline thickness & 03 & 0.2 & $3^{b}$ \\
\hline & & & \\
\hline Haugh unit & $76.13 \pm 0.07^{a}$ & $71.96 \pm 0.83^{b}$ & $78.02 \pm 0.5$ \\
\hline
\end{tabular}

Values are expressed as mean \pm standard error, a,b,c Values within the same column with different superscripts differ significantly $(p<0.05)$

the other genetic strain of birds. Nishibari fowl had significantly higher Haugh unit than Nicorock but did not differ with Nicobari.

Egg quality traits of different genetic strains reared under backyard system of management are presented in Table-3. Egg weight of Nicorock was significantly higher than Nicobari, but not with Nishibari. Whereas, the yolk height of Nicobari was significantly higher in comparison to Nicorock and Nishibari, no significant variations in yolk diameter and yolk weight were found among the three groups. Albumen weight of Nishibari was significantly lower in comparison to the other groups. Shell thickness and shape index of Nicobari was significantly higher in comparison to other genetic groups. No significant variation in Haugh unit was found among the three groups.

\section{Discussion}

Effect of genotype on egg quality parameters were reported by various previous workers [5-9]. In general, the egg weight of indigenous birds was found to be low as compared to exotic layers or broilers; however, we observed higher egg weight of Nicobari crosses than the exotic varieties/strains in this study. This might be due to the utilization of exotic germplasm for the development of these cross varieties [10]. Islam et al. [11] reported significant differences in egg weight and quality traits of indigenous Naked Neck and indigenous full feathered birds which were consistent with the results of the present study. In the present study, average egg weights under backyard condition were $43.01 \pm 1.16 \mathrm{~g}$ for Nicobari, $48.60 \pm 1.04 \mathrm{~g}$ for Nicorock
Table-3: Egg quality traits of Nicobari and Cross Nicobari fowl under backyard system of management.

\begin{tabular}{lccc}
\hline Parameters & $\begin{array}{c}\text { Nicobari } \\
(15)\end{array}$ & $\begin{array}{c}\text { Nicorock } \\
\text { (15) }\end{array}$ & $\begin{array}{c}\text { Nishibari } \\
\text { (15) }\end{array}$ \\
\hline
\end{tabular}

Egg weight $(\mathrm{g}) \quad 43.01 \pm 1.16^{\mathrm{b}} \quad 48.60 \pm 1.04^{\mathrm{a}} \quad 43.48 \pm 1.38^{\mathrm{ab}}$ Egg length $(\mathrm{mm}) \quad 51.38 \pm 0.69^{\mathrm{b}} \quad 54.59 \pm 0.48^{\mathrm{a}} \quad 52.01 \pm 0.77^{\mathrm{b}}$

$\begin{array}{llll}\text { Egg width }(\mathrm{mm}) & 35.42 \pm 0.68 & 35.32 \pm 0.30 & 34.14 \pm 0.59\end{array}$

Shape index $\quad 69.03 \pm 1.51^{\text {a }} 65.26 \pm 0.93^{\mathrm{b}} \quad 65.68 \pm 1.04^{\mathrm{b}}$

Yolk diameter $\quad 37.95 \pm 0.64 \quad 39.66 \pm 1.31 \quad 37.14 \pm 0.84$

( $\mathrm{mm}$ )

Yolk height $\quad 12.50 \pm 0.43^{\mathrm{a}} \quad 10.88 \pm 0.17^{\mathrm{b}} \quad 10.79 \pm 0.18^{\mathrm{b}}$

( $\mathrm{mm}$ )

Yolk weight $(\mathrm{g}) \quad 15.46 \pm 0.74 \quad 16.23 \pm 0.78 \quad 15.51 \pm 1.22$

$\begin{array}{llll}\text { Yolk \% } & 35.07 \pm 0.95 & 34.64 \pm 1.59 & 37.41 \pm 2.55\end{array}$

$\begin{array}{llll}\text { Yolk index } & 0.33 \pm 0.02^{\mathrm{a}} & 0.27 \pm 0.01^{\mathrm{b}} & 0.29 \pm 0.01^{\mathrm{b}}\end{array}$

Albumen height $\quad 5.74 \pm 0.34 \quad 5.34 \pm 0.11 \quad 5.48 \pm 0.08$

( $\mathrm{mm}$ )

Albumen weight $23.02 \pm 0.62^{\mathrm{a}} 25.00 \pm 1.03^{\mathrm{a}} \quad 20.64 \pm 2.33^{\mathrm{b}}$ (g)

Albumen \% $\quad 52.49 \pm 1.64 \quad 53.00 \pm 1.68 \quad 49.85 \pm 3.98$

Shell weight $(\mathrm{g}) \quad 4.74 \pm 0.25 \quad 5.59 \pm 0.20 \quad 5.25 \pm 0.50$

Shell thickness $\quad 0.39 \pm 0.08^{\mathrm{a}} \quad 0.29 \pm 0.03^{\mathrm{b}} \quad 0.28 \pm 0.04^{\mathrm{b}}$

( $\mathrm{mm})$

$\begin{array}{llll}\text { Shell \% } & 11.35 \pm 0.51 & 11.93 \pm 0.60 & 12.73 \pm 1.54\end{array}$

$\begin{array}{llll}\text { Haugh unit } \quad 78.78 \pm 2.58 & 76.32 \pm 0.97 & 78.14 \pm 1.23\end{array}$

Values are expressed as mean \pm standard error. ${ }^{a, b}$ Values within the same column with different superscripts differ significantly $(p<0.05)$

and $43.48 \pm 1.38 \mathrm{~g}$ for Nishibari (Table-2) which were higher than that of Kadaknath [12] but lower than reported in Indian White leghorn Izatnagar (IWH) [13] under field conditions in India. Kadaknath is a black meat chicken breed of India, commonly available in jet-black, penciled and golden color. The bird is very popular among the tribal people of India mainly due to its adaptability to the local environment, disease resistance property, tasty meat quality, texture and flavor. It is considered not only a delicacy of distinctive taste, but also of medicinal value. IWH [13] is a pure line of white Leghorn, maintained at Directorate of Poultry Research. This breed of poultry is also very adaptable to the field conditions of India. The higher egg weight of Nicorock and Nishibari might be due to the presence of exotic germplasm in these cross birds [10].

Shape index is the ratio of the width to length of the egg. In the present study, the average shape index values recorded ranged from $65.50 \pm 1.48$ in Nicobari to $66.45 \pm 1.46$ in Nishibari bird under intensive system (Table-1) and from 65.68 \pm 1.04 in Nicorock to $69.03 \pm 1.51$ in Nicobari bird under backyard condition (Table-2). Higher shape index of 74.35 was reported by Parmar et al. [12] in Kadaknath. Chatterjee et al. [14] observed higher shape index, 80.76 \pm 1.32 for IWK (Indian White Legorn K strain) and lower indices for IWI (Indian White Leghorn I-strain) (73.77 \pm 3.08 ) and IWH (72.67 \pm 7.56$)$ strains of White Leghorn.

Albumen weight of Nicobari and it crosses varied from $27.65 \pm 0.53 \mathrm{~g}$ to $31.98 \pm 1.12 \mathrm{~g}$ which agrees with the findings reported by Chatterjee et al. [15] in indigenous fowls of Andaman but higher than the values reported in Kadaknath (20.74g) [12]. The 
Nicorock bird studied was the cross of exotic and improved chicken varieties with Nicobari fowl that might be the reason for its better albumen weight. The egg albumen height ranged from $5.34 \pm 0.11 \mathrm{~mm}$ in Nicorock to $5.74 \pm 0.34 \mathrm{~mm}$ in Nicobari in backyard system (Table-2) and 5.26 $\pm 0.09 \mathrm{~mm}$ in Nicorock to $5.64 \pm 0.09 \mathrm{~mm}$ in Nishibari in intensive system (Table-1). Fayeye et al. [16] reported the albumen height of Fulani-ecotype chicken as $4.92 \pm 0.79 \mathrm{~mm}$ which was lower than the values of the present study.

Yolk weight in the Nicobari and its crosses varied from $13.36 \pm 0.23 \mathrm{~g}$ in Nicobari to $18.17 \pm 0.71 \mathrm{~g}$ in Nicorock that differed significantly. A lower estimate of yolk weight (15.18 g) was observed in Kadaknath [12]. Chatterjee et al. [15] reported higher yolk weights in Naked Neck, Barred Desi and Frizzle Fowl and lower yolk weights in Brown and Black Nicobari breeds of Andaman and Nicobar Islands. The egg yolk height ranged from $11.70 \pm 0.12 \mathrm{~mm}$ in Nishibari to $13.80 \pm 0.73 \mathrm{~mm}$ in Nicorock in intensive system (Table-1) and $10.79 \pm 0.18 \mathrm{~mm}$ in Nishibari to $12.50 \pm 0.43 \mathrm{~mm}$ in Nicobari in backyard system (Table-2). Fayeye et al. [16] reported the yolk height of Fulani-ecotype chicken as $14.27 \pm 1.45 \mathrm{~mm}$ which was higher than the results reported in the present study. The egg yolk diameter ranged from $37.14 \pm 0.84 \mathrm{~mm}$ in Nishibari to $37.95 \pm 0.64 \mathrm{~mm}$ in Nicobari in backyard system (Table-2) and $36.65 \pm 0.02 \mathrm{~mm}$ in Nishibari to $40.89 \pm 0.67 \mathrm{~mm}$ in Nicorock in intensive system (Table-1). Yolk index values were significantly $(\mathrm{p}<0.05)$ influenced by the genetic groups in the present study (Tables 1 and 2). The yolk indices ranged from $0.30 \pm 0.01$ (Nicobari) to $0.33 \pm 0.03$ (Nicorock) under intensive system (Table-1). Higher yolk indices of $0.41 \pm 0.01$ to $0.45 \pm 0.01$ in Nicobari varieties of Andaman were observed by Padhi et al. [17]. Parmar et al. (2006) also observed higher yolk index (0.37) in Kadaknath birds [12]. The difference in yolk ratio among genetic groups in the present study agrees with the reports of Pandey et al. [18] that strain differences existed in yolk of eggs. Cobb 500, RIR and Deshi eggs were healthier than Fayoumi and Sonali eggs that contained higher yolk ratio [19]. Taken together, the results of the present study indicate strain specific differences in the yolk characteristics.

The shell weight ranged from $6.01 \pm 0.10 \mathrm{~g}$ in Nicorock to $6.41 \pm 0.21 \mathrm{~g}$ in Nishibari in intensive system (Table- 1 ) and $4.74 \pm 0.25 \mathrm{~g}$ in Nicobari to $5.59 \pm 0.20 \mathrm{~g}$ in Nicorock in backyard system (Table-2), which was consistent with the reports in Naked Neck and White Leghorn [18]. Chatterjee et al. [15] reported the non-significant breed difference in shell weight for six indigenous chicken breeds from Andamans. The shell thickness varied significantly $(p<0.05)$ among different genetic strains in the present study. Shell thickness was higher in case of Nicobari $(0.39 \pm 0.04 \mathrm{~mm})$ and lower in Nicorock $(0.29 \pm 0.05 \mathrm{~mm})$ under intensive system; whereas, higher in case of Nicobari $(0.39 \pm 0.08 \mathrm{~mm})$ and lower in Nishibari $(0.28 \pm 0.04 \mathrm{~mm})$ under backyard system. The mean shell thickness of $0.31 \mathrm{~mm}$ in Kadaknath [12] and $0.31 \mathrm{~mm}$ in Naked Neck [17] was reported. The shell thickness of Nicobari eggs in the present study was found to be higher than reported in other indigenous birds like Kadaknath and Naked Neck. The higher shell thickness in the birds developed for backyard poultry was an indicator for their better suitability for rural/backyard/free range farming. The cross birds used in the study had better egg production, but the shell thickness reduced from the parental stock. Wani et al. [20] reported lower shell thickness $(0.32 \mathrm{~mm})$ for Vanaraja birds than the values of the present study. Non-significant variation in shell thickness between reciprocal crosses of ILI 80 and Brown Nicobari was observed by Chatterjee et al. [21].

Haugh unit is a measure of albumen quality that determines the quality of the egg. In the present experiment, the average Haugh unit ranged from $71.96 \pm 0.83$ (Nicorock) to $78.02 \pm 0.53$ (Nishibari) among the genetic groups under intensive system (Table-1) and from 76.32 \pm 0.97 (Nicorock) to $78.78 \pm 2.58$ (Nicobari) under backyard system (Table-2), which were significantly higher than that of White Leghorn strains (59.62-71.62) reported by Chatterjee et al. [14]. The genotypic differences in Haugh unit obtained in this study are consistent with the report of Zaman et al. [22] where different Haugh unit values were observed for various strains of birds. Differences in Haugh unit among different genetic groups were also reported in main and reciprocal crossbred Normal Local, Naked Neck and Frizzle Chicken X Exotic broiler in humid tropical climate of Nigeria [23]. Parmar et al. [12] reported wide range of Haugh unit values (62.58-90.00) for Kadaknath birds under field conditions in India, which was consistent with the results of the present study. The Haugh unit values obtained for the Nicobari and cross Nicobari (Nicorock and Nishibari) eggs were above 70. The presence of exotic inheritance in Nicobari crosses [10] might be the reason for higher Haugh unit score in the present study.

\section{Conclusion}

The present study revealed that egg quality traits differed significantly among various genetic strains of chicken, both in intensive system and backyard condition. It was found that husbandry practices affected egg weight of birds; the egg weights of all three genetic strains were found less under backyard system than intensive system. The results of the study will be helpful for determination of quality of eggs of different indigenous chicken varieties of Andaman and Nicobar Islands.

\section{Authors' Contributions}

NCC and GP were involved in the design of the experiment. The experiment was done by NCC and AKD. AKD, AK, MSK and NR revised the final draft 
of the manuscript. All authors read and approved the final manuscript.

\section{Acknowledgments}

The authors are thankful to the Director, Central Island Agricultural Research Institute (CIARI), Port Blair for providing all facilities including financial assistance and Head of the Department, Animal Science Division to complete the study successfully. The authors are also thankful to the programme coordinator, KVK-CIARI for full co-operation.

\section{Competing I nterests} interests.

The authors declare that they have no competing

\section{References}

1. Niranjan, M., Sharma, R.P., Rajkumar, U., Chatterjee, R.N., Reddy, B.N. and Battacharya, T.K. (2008) Egg quality traits in chicken varieties developed for backyard poultry farming in India. Livest. Res. Rural Dev., 20(12).

2. Kundu, A., Sujatha, T., Jeyakumar, S., Sunder, J., Kundu, M.S., Verma, S.K., De, A.K. and Srivastava, R.C. (2012) Diversity and conservation of indigenous poultry germplasm of Andaman and Nicobar Islands. Ecology of Faunal Communities on the Andaman and Nicobar Islands. Springer Publication, Berlin, New York.

3. Ahlawat, S.P.S. and Chatterjee, R.N. (2002) Conservation of indigenous poultry germplasm of Anadaman and Nicobar Islands. National Workshop on Characterization and Conservation of Indigenous Poultry Germplasm. Central Agricultural Research Institute, Andman and Nicobar Islands. p9-14.

4. Ahmadi, F. and Rahimi F. (2011) Factors affecting quality and quantity of egg production in laying hens: A review. World Appl. Sci. J., 12(3): 372-384.

5. Bonekamp, R.P.R.T., Lemme, A., Wijtten, P.J.A. and Sparla, J.K.W.M. (2010) Effects of amino acids on egg number and egg mass of brown (heavy breed) and white (light breed) laying hens. Poult. Sci., 89(3): 522-529.

6. Jones, D.R., Musgrove, M.T., Anderson, K.E. and Thesmar, H.S. (2010) Physical quality and composition of retail shell eggs. Poult. Sci., 89(3): 582-587.

7. Momoh, O.M., Ani, A.O. and Ugwuowo, L.C. (2010) Part-period egg production and egg quality characteristics of two ecotypes of Nigerian local chicken and their $F_{1}$ crosses. Int. J. Poult. Sci., 9(8): 744-748.

8. Alewi, M., Melesse, A. and Teklegiorgis, Y. (2012) Crossbreeding effect on egg quality traits of local chickens and their f1 crosses with Rhode Island Red and Fayoumi chicken breeds under farmers' management conditions. J. Anim. Sci. Adv., 2(8): 697-705.

9. Haunshi, S., Niranjan, M., Shanmugam, M., Padhi, M.K., Reddy, M.R., Sunitha, R., Rajkumar, U. and Panda, A.K.
(2011) Characterization of two Indian native chicken breeds for production, egg and semen quality, and welfare traits. Poult. Sci., 90(2): 314-320.

10. Sharma, R.P. and Chatterjee, R.N. (2006) Diversity in indigenous poultry genetic resources and their conservation. Proceedings of Biodiversity Awareness Workshop on Animal Genetic Resources \& Conservation. Karnal, India.

11. Islam, M.A., Bulbul, S.M., Seeland, G. and Islam, A.B.M.M. (2001) Egg quality of different chicken genotypes in summer and winter. Pak. J. Biol. Sci., 4: 1411-1414.

12. Parmar, S.N.S., Thakur, M.S., Tomar, S.S. and Pillai, P.V.A. (2006) Evaluation of egg quality traits in indigenous Kadaknath breed of poultry. Livest. Res. Rural. Dev., 18(9).

13. Mathivanam, R. and Selvaraj, P. (2003) Influence of dietary chromium on egg production and quality parameters in layers. Indian. J. Poult. Sci., 38: 51-53.

14. Chatterjee, R.N., Sharma, R.P., Niranjan, M., Reddy, B.L.N. and Mishra, A. (2006) Genetic studies on egg quality traits in different White Leghorn populations. Indian. J. Anim. Genet. Breed., 27: 51-54.

15. Chatterjee, R.N., Rai, R.B., Kundu, A., Senani, S. and Sundar, J. (2007) Egg quality traits in indigenous breeds of chicken of Andaman. Indian. Vet. J., 84(2): 206-208.

16. Fayeye, T.R., Adesiyan, A.B. and Olugbami, A.A. (2005) Egg traits, hatchability and early growth performance of the Fulani-ecotype chicken. Livest. Res. Rural Dev., 17.

17. Padhi, M.K., Rai, R.B., Senani, S. and Saha, S.K. (1998) Assessment of egg quality characteristics in white leghorn layers. Indian. J. Poult. Sci., 33: 113-115.

18. Pandey, N.K.M., Mahaparta, C.M., Verma, S.S. and Johar, A. (1986) Effect of strain on physical egg quality characteristics in white leghorn chickens. Indian. J. Poult. Sci., 21: 304-307.

19. Islam, M.S. and Dutta, R.K. (2010) Egg quality traits of indigenous, exotic and crossbred chickens in Rajshahi, Bangladesh. J. Life. Earth. Sci., 5: 63-67.

20. Wani, S.A., Malik, A.H., Bhat, G.A., Khan, A.A., Salahuddin, M., Pal, M.A. and Sofi, A.H. (2007) Seminar on backyard poultry farming for women empowerment and nutritional security. Sher-e-Kashmir University of Agricultural Sciences and Technology of Kashmir, Srinagar.

21. Chatterjee, R.N., Rai, R.B., Pramanik, S.C., Sundar, J., Senani, S. and Kundu, A. (2007) Comparative growth, production, egg and carcass traits of different crosses of Brown Nicobari with White Leghorn under intensive and extensive management systems in Andamans, India. Livest. Res. Rural. Dev., 19(12).

22. Zaman, M.A., Sorensen, P. and Howlider, M.A.R. (2004) Egg production performance of a breed and three crossbreds under semi-scavenging systems of management. Livest. Res. Rural. Dev., 16.

23. Nwachukwu, E.N., Ibe, S.N. and Ejekwu, K. (2006) Short term egg production and egg quality characteristics of main and reciprocal crossbred normal local, naked Neckand frizzle chicken $\mathrm{X}$ exotic broiler breeder stock in a humid tropical climate. J. Anim. Vet. Adv., 5(7): 547-551. 